\title{
Cu-ZSM-5 Zeolites for the Formation of Methanol from Methane and Oxygen: Probing the Active Sites and Spectator Species
}

\author{
Nadzeya V. Beznis • Bert M. Weckhuysen • \\ Johannes H. Bitter
}

Received: 12 April 2010/ Accepted: 19 May 2010/Published online: 4 June 2010

(C) The Author(s) 2010. This article is published with open access at Springerlink.com

\begin{abstract}
A series of Cu-ZSM-5 zeolites was prepared by varying nature of the charge compensating cation, copper precursor, copper loading, and $\mathrm{pH}$. The materials were tested for the oxidation of methane to methanol using oxygen. A linear relationship between the amount of methanol produced over Cu-ZSM-5 zeolites from methane and oxygen and a UV-Vis-NIR DRS charge transfer band at $22,700 \mathrm{~cm}^{-1}$ is reported irrespective of the synthesis route used. The absolute intensity of the $22,700 \mathrm{~cm}^{-1}$ band is always low, indicating a low number of active sites in the samples. In all studied Cu-ZSM-5 zeolites at least two copper species were present: (a) $\mathrm{Cu}-\mathrm{O}$ clusters dispersed on the outer surface of ZSM-5 and (b) highly dispersed copper-oxo species inside the channels, a minority fraction in the sample. By relating catalytic activity to FT-IR data of adsorbed pivalonitrile, visualizing $\mathrm{Cu}-\mathrm{O}$ particles on the outer surface of the zeolite, and subsequently adsorbed NO, indicative of the $\mathrm{Cu}-\mathrm{O}$ species inside the zeolite channel, it was concluded that $\mathrm{Cu}-\mathrm{O}$ species on the outer surface are not involved in the oxidation reaction, while copper inside the channels are responsible for the selective conversion of methane to methanol.
\end{abstract}

Keywords Methanol - Methane activation - Cu-ZSM-5 . $\mu$-Oxo dicopper cluster - UV-Vis spectroscopy .

FT-IR with pivalonitrile and NO

Electronic supplementary material The online version of this article (doi:10.1007/s10562-010-0380-6) contains supplementary material, which is available to authorized users.

N. V. Beznis · B. M. Weckhuysen · J. H. Bitter $(\bowtie)$ Inorganic Chemistry and Catalysis Group, Department of Chemistry, Faculty of Sciences, Utrecht University, Sorbonnelaan 16, 3584 CA Utrecht, The Netherlands e-mail: j.h.bitter@uu.nl

\section{Introduction}

Direct partial oxidation of methane to methanol poses one of the greatest challenges in heterogeneous catalysis because the driving force to full combustion is high [1-5]. Methanol is currently produced via a multi-step process, i.e., methane $\rightarrow$ syngas $\rightarrow$ methanol [5-8]. Although this process is highly efficient, it has to be performed at large scale due to the high capital costs of syngas production [9]. Thus, for small-scale applications at e.g. remote locations, a new method is needed and a one step methane oxidation to methanol would be advantageous.

Metal-containing zeolites, in particular Fe-ZSM-5 and Cu-ZSM-5, hold great potential for the direct partial oxidation of methane to oxygenates. Fe-ZSM-5 was shown to be able to oxidize benzene to phenol and methane to methanol [10-15]. This indicates that these catalysts are able to activate hydrocarbons and form active oxygen species in such a way that complete oxidation of the reactants towards carbon dioxide and water is prevented. The use of $\mathrm{N}_{2} \mathrm{O}$ as an oxidant was essential and claimed to lead to a special type of reactive surface oxygen species, often called $\alpha$-oxygen [10-12]. In a similar manner, Cu-ZSM-5 zeolites are able to convert benzene to phenol $[16,17]$ and methane to methanol $[18,19]$ using molecular oxygen as an oxidant. Recently, we showed that Co-ZSM-5 zeolites can convert methane to oxygenates using oxygen [20]. The activity and selectivity depended on the nature of cobalt species present in materials. Cobalt in ion-exchange position was selective towards formaldehyde; while cobalt oxide species (both $\mathrm{CoO}, \mathrm{Co}_{3} \mathrm{O}_{4}$ ) were selective towards methanol [20].

Although Cu-ZSM-5 zeolites are selective towards methanol formation, the mechanism of the reaction is still under debate. The active site in these $\mathrm{Cu}-\mathrm{ZSM}-5$ zeolites is 
considered to be represented by a UV-Vis-NIR diffuse reflectance spectroscopy (DRS) absorption band at $22,700 \mathrm{~cm}^{-1}$. Several assignments have been reported for this band. Some authors ascribed the band to the presence of $(\mathrm{Cu}-\mathrm{O}-\mathrm{Cu})^{2+}$ species [21-23], while other groups assigned it to a bis( $\mu$-oxo) dicopper species $[18,19,24$, 25]. Recently, Woertink et al. [26] presented additional information on the origin of copper species using a combination of resonance Raman (rR) spectroscopy and density functional theory (DFT). It was concluded that the oxygen activated copper core is defined as a bent mono-( $\mu$-oxo) dicopper cluster. When true the intensity of this UV-VisNIR DRS band should be directly related to the methane oxidation activity of the Cu-ZSM-5 sample which has not been, to the best of our knowledge, shown before. This will be investigated in the current work.

From the existing literature $[18,19]$ it is clear that the $\mathrm{Cu}-\mathrm{O} \mathrm{CT}$ band has an unusual low intensity in comparison with the $\mathrm{d}-\mathrm{d}$ transition band of the same sample. In general, a CT band is at least two orders of magnitude more intense [27], whereas for most Cu-ZSM-5 zeolites the CT band and the $\mathrm{d}-\mathrm{d}$ transition have similar intensities. This lead us to hypothesize that the species related to the CT band are only a minority species in the sample and other species must be present. Therefore, we report here a characterization study of Cu-ZSM-5 zeolites with the aim of identifying the different copper species present and establishing a quantitative structure-performance relation. For this purpose, we have investigated a series of Cu-ZSM-5 zeolites varying in their copper loading and nature of copper precursor, $\mathrm{pH}$ and nature of the charge compensating cation to vary the intensity of the $22,700 \mathrm{~cm}^{-1}$ band and evaluated their activity for methanol production from methane and oxygen.

\section{Experimental}

\subsection{Sample Preparation}

$\mathrm{NH}_{4}$-ZSM-5 (ZEOLYST, Si/Al = 17.5) was converted to Na-ZSM-5 via three times ion-exchange using $0.1 \mathrm{M}$ sodium nitrate (98\%, Acros Organics) at ambient temperature for $24 \mathrm{~h}$. After ion-exchange the sample was washed and dried overnight at $333 \mathrm{~K}$. Copper was introduced by ion-exchange using aqueous solutions $(300 \mathrm{~mL}$ solution, $3 \mathrm{~g}$ zeolite) of copper acetate (98\%, Acros Organics) of different concentrations (Table 1) at room temperature for $24 \mathrm{~h}$ (the $\mathrm{pH}$ of the ion-exchange solution was $\sim 6$ ). Next the samples were washed and dried at $393 \mathrm{~K}$. The samples are denoted as $\mathrm{Cu}-\mathrm{A}-\mathrm{L}$, where $\mathrm{L}$ is the copper loading in wt $\%$. Similar procedures were used to introduce copper by ion-exchange using copper nitrate (98\%, Acros Organics) and copper chloride (98\%, Acros Organics) solutions (the $\mathrm{pH}$ of both solutions were $~ 4.5$ ). All samples were washed and dried at $393 \mathrm{~K}$. The samples are denoted as $\mathrm{Cu}-\mathrm{N}-\mathrm{L}$ and $\mathrm{Cu}-\mathrm{C}-\mathrm{L}$, respectively, where $\mathrm{L}$ is the copper loading in $\mathrm{wt} \%$.

In addition, samples with varying nature of the charge compensating cations were prepared. First, X-ZSM-5 zeolites $\left(\mathrm{X}=\mathrm{Na}^{+}, \mathrm{K}^{+}, \mathrm{Rb}^{+}, \mathrm{Ba}^{2+}, \mathrm{Ca}^{2+}, \mathrm{Mg}^{2+}\right.$, and $\mathrm{Sr}^{2+}$ ) were prepared starting from $\mathrm{NH}_{4}$-ZSM-5 (ZEOLYST, $\mathrm{Si} / \mathrm{Al}=17.5$ ) via three times ion-exchange at room temperature for $24 \mathrm{~h}$ using the corresponding metal nitrates (for $\mathrm{Na}, \mathrm{K}, \mathrm{Sr}, \mathrm{Ba}$, and $\mathrm{Rb}$ ) or acetates (for $\mathrm{Ca}, \mathrm{Ba}$ ). Copper was introduced by ion-exchange using a $0.02 \mathrm{M}$ copper acetate solution. These samples are denoted as $\mathrm{Cu}-\mathrm{A}-\mathrm{X}-\mathrm{L}$, where $\mathrm{X}$ is the charge compensating cation and $\mathrm{L}$ is the copper loading in $\mathrm{wt} \%$.

Cu-ZSM-5 zeolites were also prepared using copper acetate solutions of $\mathrm{pH} 3.5-5$. Acetic acid was used to adjust the $\mathrm{pH}$ of starting $0.02 \mathrm{M}$ copper acetate solution. After that Na-ZSM-5 was introduced into the solution and the ion-exchange procedure was performed; the $\mathrm{pH}$ of the slurry slightly decreased. The samples are denoted as $\mathrm{Cu}-\mathrm{A}-\mathrm{L}-\mathrm{P}$, where $\mathrm{L}$ is the copper loading in wt $\%$ and $\mathrm{P}$ is the $\mathrm{pH}$ of the solution used for ion-exchange.

\subsection{Catalyst Characterization and Testing}

Copper loadings were determined by Atomic Absorption Spectroscopy (AAS) using a VARIAN Spectra AA-20 instrument. $10 \mathrm{mg}$ of the Cu-ZSM-5 zeolite was dissolved in $0.1 \mathrm{M} \mathrm{HF}$ to prepare the solutions for AAS measurements. Surface areas and pore volumes were determined by $\mathrm{N}_{2}$-physisorption using a Micromeritics ASAP 2400 instrument. Surface areas were calculated by using the BET model with micro- and macropores described by the Horvath-Kawazoe and BJH models, respectively. X-Ray Diffraction (XRD) patterns of the Cu-ZSM-5 zeolites were recorded using a Nonius PDS 120 powder diffraction apparatus with Co $\mathrm{K} \alpha$ radiation $(\lambda=1.78897 \AA$ ).

Catalytic activity, in batch mode, and UV-Vis-NIR DRS experiments were simultaneously performed in a specially designed quartz reactor equipped with a UV-VisNIR transparent window [28]. Before reaction the samples (1.0 g, grain size $0.2-0.5 \mathrm{~mm}$ ) were mild calcined [29] in air $(1000 \mathrm{~mL} / \mathrm{min})$ at $823 \mathrm{~K}$ (heating ramp of $0.5 \mathrm{~K} / \mathrm{min}$ ). After calcination the samples were cooled to RT and flushed with He. Subsequently, the samples were heated to $423 \mathrm{~K}$ (heating ramp of $10 \mathrm{~K} / \mathrm{min}$ ) in methane $(8 \%$ in $\mathrm{He}$; $25 \mathrm{~mL} / \mathrm{min}$ ) and kept at that temperature for $25 \mathrm{~min}$.

After reaction with methane methanol was collected by extraction. $0.2 \mathrm{~g}$ of the sample was stirred in $0.5 \mathrm{~mL}$ solvent for $1 \mathrm{~h}$. Different solvents were explored: acetonitrile dried over $\mathrm{MgSO}_{4}$ (99.99\%, Acros Organics), an 
Table 1 Overview of the Cu-ZSM-5 zeolites under investigation and their preparation method and amount of methanol produced

\begin{tabular}{|c|c|c|c|c|c|c|}
\hline Copper precursor & Samples & Conc prec. $\mathrm{M}$ & $\mathrm{pH}$ & $\begin{array}{l}\mathrm{Cu} \text { loading, } \\
\mathrm{wt}^{\mathrm{a}} \mathrm{a}^{\mathrm{a}}\end{array}$ & $\begin{array}{l}\text { CT intensity, } \\
\text { K-M units }\end{array}$ & $\begin{array}{l}\text { Methanol production, } \\
\mathrm{mmol} / \mathrm{mol} \mathrm{Cu}\end{array}$ \\
\hline \multirow[t]{18}{*}{ Copper acetate } & $\mathrm{Cu}-\mathrm{A}-2.2$ & 0.01 & 5.5 & 2.2 & 0.9 & 4.7 \\
\hline & $\mathrm{Cu}-\mathrm{A}-2.4$ & 0.02 & & 2.4 & 1.0 & 5.2 \\
\hline & $\mathrm{Cu}-\mathrm{A}-2.6$ & 0.05 & & 2.6 & 1.4 & 6.4 \\
\hline & $\mathrm{Cu}-\mathrm{A}-2.5$ & 0.1 & & 2.5 & 1.2 & 4.9 \\
\hline & $\mathrm{Cu}-\mathrm{A}-1.4$ & 0.005 & & 1.4 & 0 & 0 \\
\hline & $\mathrm{Cu}-\mathrm{A}-0.9$ & 0.002 & & 0.9 & 0 & 0 \\
\hline & $\mathrm{Cu}-\mathrm{A}-1.7-5.0$ & 0.02 & 5.0 & 1.7 & 0.5 & 3.0 \\
\hline & $\mathrm{Cu}-\mathrm{A}-1.6-4.5$ & & 4.5 & 1.6 & 0.2 & 2.0 \\
\hline & $\mathrm{Cu}-\mathrm{A}-1.6-4.0$ & & 4.0 & 1.6 & 0.15 & 1.6 \\
\hline & $\mathrm{Cu}-\mathrm{A}-1.5-3.5$ & & 3.5 & 1.5 & 0.1 & 1.3 \\
\hline & $\mathrm{Cu}-\mathrm{A}-\mathrm{H}-2.0$ & 0.02 & 5.5 & 2.0 & 0.6 & 3.5 \\
\hline & $\mathrm{Cu}-\mathrm{A}-\mathrm{NH}_{4}-1.9$ & & & 1.9 & 0.6 & 4.0 \\
\hline & $\mathrm{Cu}-\mathrm{A}-\mathrm{Na}-2.4$ & & & 2.4 & 1.0 & 5.2 \\
\hline & $\mathrm{Cu}-\mathrm{A}-\mathrm{K}-1.8$ & & & 1.8 & 0.6 & 4.3 \\
\hline & $\mathrm{Cu}-\mathrm{A}-\mathrm{Rb}-2.0$ & & & 2.0 & 0.6 & 3.8 \\
\hline & Cu-A-Mg-1.7 & & & 1.7 & 0.4 & 3.4 \\
\hline & $\mathrm{Cu}-\mathrm{A}-\mathrm{Sr}-1.4$ & & & 1.4 & 0.2 & 1.8 \\
\hline & Cu-A-Ba-1.6 & & & 1.6 & 0.2 & 2.0 \\
\hline \multirow[t]{4}{*}{ Copper nitrate } & $\mathrm{Cu}-\mathrm{N}-1.6$ & 0.01 & 4.5 & 1.6 & 0.2 & 2.7 \\
\hline & $\mathrm{Cu}-\mathrm{N}-1.8$ & 0.02 & & 1.8 & 0.3 & 1.7 \\
\hline & $\mathrm{Cu}-\mathrm{N}-1.9$ & 0.05 & & 1.9 & 0.4 & 2.0 \\
\hline & $\mathrm{Cu}-\mathrm{N}-2.0$ & 0.1 & & 2.0 & 0.4 & 2.2 \\
\hline \multirow[t]{4}{*}{ Copper chloride } & $\mathrm{Cu}-\mathrm{C}-1.7$ & 0.01 & 4.5 & 1.7 & 0.3 & 2.3 \\
\hline & $\mathrm{Cu}-\mathrm{C}-1.7$ & 0.02 & & 1.7 & 0.3 & 2.6 \\
\hline & $\mathrm{Cu}-\mathrm{C}-2.0$ & 0.05 & & 2.0 & 0.4 & 2.9 \\
\hline & $\mathrm{Cu}-\mathrm{C}-1.9$ & 0.1 & & 1.9 & 0.4 & 2.7 \\
\hline
\end{tabular}

${ }^{a}$ At $2 \mathrm{wt} \% \mathrm{Cu}$ loading and a $\mathrm{Si} / \mathrm{Al}$ ratio of 17 results in a $\mathrm{Cu} / \mathrm{Al}$ ratio of 0.4

acetonitrile-water mixture (50:50\%), ethanol $(99.9 \%$, Merck), and hexane (99.9\%, Merck), of which ethanol was the most efficient. The product composition was determined by a Shimadzu 2010 gas chromatograph equipped with a CP-WAX $52 \mathrm{CB}$ column (50 m and $0.32 \mathrm{~mm}$ ID) and a liquid sampler AOC-20i.

The in situ UV-Vis-NIR DRS measurements were carried out using a Varian Cary 500 spectrometer in the range $5,000-50,000 \mathrm{~cm}^{-1}(200-2,200 \mathrm{~nm})$. In order to eliminate the contributions of the zeolite material, a DR UV-VisNIR spectrum of a dehydrated ZSM-5 zeolite sample was subtracted from all Cu-ZSM-5 zeolites. DR UV-Vis-NIR data are reported in Kubelka-Munk (K-M) units [30].

Transmission Electron Microscopy (TEM) was performed on a Tecnai 20 (FEI) equipped with a field emission gun and operated at $200 \mathrm{kV}$. A small amount of the sample was positioned on a carbon microgrid supported on nickel. Elemental composition was obtained by Energy Dispersive analysis of X-rays (EDX) performed through a LINK EDX system.
FT-IR spectra of adsorbed probe molecules were recorded on a Perkin Elmer 2000 FT-IR instrument. Samples were pressed in self-supporting wafers (around $20 \mathrm{mg}$ ) and activated by outgassing in vacuum at $623 \mathrm{~K}$. Next the sample was exposed to pivalonitrile vapor (Acros Organics, 98\%) at $323 \mathrm{~K}$ and $7 \mathrm{mbar}$ for $20 \mathrm{~min}$. Subsequently, adsorption of NO (10\% in $\mathrm{He} ; 9$ mbar) was performed at $323 \mathrm{~K}$ for $20 \mathrm{~min}$. Data were baseline-corrected and the intensity of a spectrum was normalized at the zeolite overtones $\left(1,950-2,050 \mathrm{~cm}^{-1}\right)$.

\section{Results and Discussion}

Table 1 summarizes some details on the synthesis procedure and characteristics of the Cu-ZSM-5 zeolites under investigation. $\mathrm{Cu}$ loadings were the highest $(>2 \mathrm{wt} \%)$ when copper acetate was used as precursor most likely as the result of the higher $\mathrm{pH}$ of the acetate solution (around six) as compared to that of the copper chloride or copper nitrate 
solutions (for both 4.5). This was confirmed by the fact that the samples prepared at lower $\mathrm{pH}$ contained a lower amount of copper.

For the $\mathrm{Cu}-\mathrm{X}-\mathrm{L}$ zeolites elemental analysis revealed that zeolites exchanged with divalent charge compensating cations contain always less copper (about $1.5 \mathrm{wt} \% \mathrm{Cu}$ ) than the zeolite samples having monovalent cations (about 2 wt $\% \mathrm{Cu}$ ), though the intended weight loading was the same.

All copper-loaded zeolites had a BET surface area of around $320 \mathrm{~m}^{2} / \mathrm{g}$ with a micropore volume of about $0.12 \mathrm{~mL} / \mathrm{g}$, which is only slightly lower in comparison with the parent zeolite $\left(360 \mathrm{~m}^{2} / \mathrm{g}, 0.13 \mathrm{~mL} / \mathrm{g}\right.$, respectively).

The XRD patterns of all copper-loaded ZSM- 5 zeolites after calcination were identical to and well represented by that of parent Na-ZSM-5, indicating no detectable damage of the ZSM-5 structure during the preparation. No additional peaks due to the presence of copper oxide phases were found within the experimental sensitivity of XRD.

Figure 1 shows the UV-Vis-NIR DRS spectra for $\mathrm{Cu}-\mathrm{A}$ $\mathrm{L}$ zeolites having different copper loadings. Absorption bands were found at 14,000 and $22,700 \mathrm{~cm}^{-1}$. The band at $14,000 \mathrm{~cm}^{-1}$ has been assigned to $\mathrm{d}-\mathrm{d}$ transition of $\mathrm{Cu}^{2+}$ in (pseudo-) octahedral environment [21, 31, 32]. As mentioned above for the band at $22,700 \mathrm{~cm}^{-1}$ several assignments have been reported. It is ascribed to the charge transfer band from $\mathrm{Cu}$ to $\mathrm{O}$ either in bis( $\mu$-oxo) dicopper $[18,19]$ or in mono-( $\mu$-oxo) dicopper species [21-23, 26]. However, as already discussed the intensity of the band at $22,700 \mathrm{~cm}^{-1}$ is exceptionally weak for a CT band; usually a CT band is at least two orders of magnitude higher in intensity compared to a $\mathrm{d}-\mathrm{d}$ transition band [27]. This indicates that only a minority of copper is present as the species giving rise to the $\mathrm{CT}$ band at $22,700 \mathrm{~cm}^{-1}$.

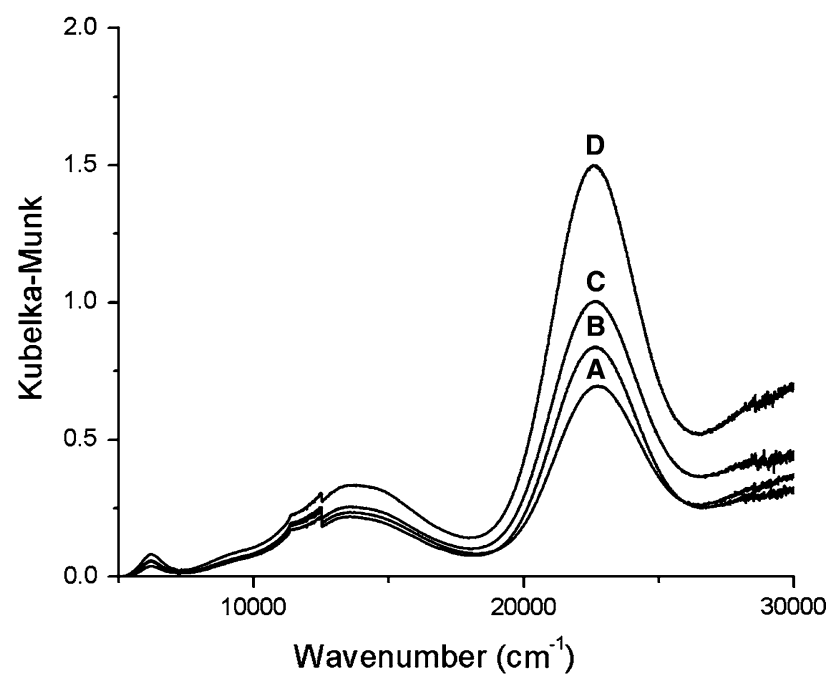

Fig. 1 UV-Vis-NIR DRS spectra of Cu-A-2.2 (a), Cu-A-2.4 (b), CuA-2.5 (c), and Cu-A-2.6 (d) after calcination in air at $823 \mathrm{~K}$
Earlier studies of Groothaert et al. [18, 19, 26] showed that the $\mathrm{CT}$ band at $22,700 \mathrm{~cm}^{-1}$ disappeared after exposing Cu-ZSM-5 to methane, after which methanol could be extracted. Based on that result it was proposed that this CT band was associated to the active site for methane oxidation to methanol over $\mathrm{Cu}-\mathrm{ZSM}-5$ zeolites. However, a quantitative relation between the intensity of the CT band and the amount of methanol produced has, to the best of our knowledge, not been reported before. When the CT band is indeed related to the active site, the intensity of the band should be linearly related to the catalytic activity. In Fig. 2 the intensity of the CT band at $22,700 \mathrm{~cm}^{-1}$ as a function of $\mathrm{Cu}$ loading for all different Cu-ZSM-5 (Cu-A-L, Cu-N-L, $\mathrm{Cu}-\mathrm{C}-\mathrm{L}, \mathrm{Cu}-\mathrm{A}-\mathrm{X}-\mathrm{L}$, and $\mathrm{Cu}-\mathrm{A}-\mathrm{L}-\mathrm{P})$ zeolites is plotted. Clearly, two regions can be distinguished. In region one no intensity of the $\mathrm{CT}$ was seen though $\mathrm{Cu}$ was present. In region two (above $1.4 \mathrm{wt} \% \mathrm{Cu}$ ) a linear increase of the $\mathrm{CT}$ band with $\mathrm{Cu}$ loading was observed. Smeets et al. [24] showed earlier that the samples with low $\mathrm{Cu}$ loading the distance between copper atoms is too large and thus, the formation of ( $\mu$-oxo) dicopper species is impossible, i.e., no CT band should be observed which is confirmed here as well. For Cu-ZSM-5 zeolites with higher copper loadings $(>1.4 \mathrm{wt} \%)$ intensity of the CT band increased linearly with increasing $\mathrm{Cu}$ loading suggesting a higher amount of potential active sites for the methane to methanol reaction for samples with a higher copper loading.

Since all samples follow the same trend irrespective of the used copper precursor, $\mathrm{pH}$ and the nature of the charge compensating cation, it was concluded that the nature of the copper species in all samples is the same. Only their amount varied among the samples. This observation also

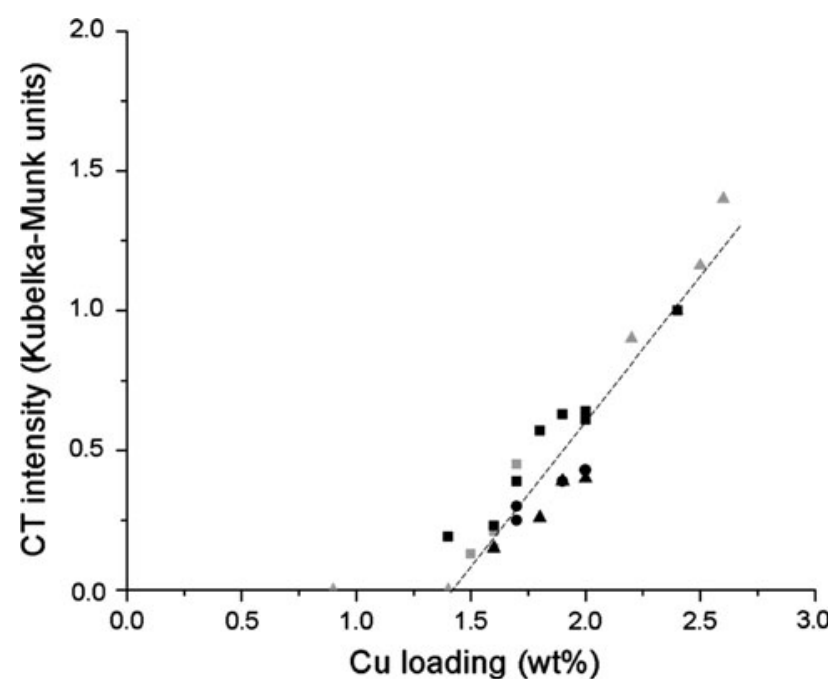

Fig. 2 CT intensity at $22,700 \mathrm{~cm}^{-1}$ as a function of $\mathrm{Cu}$ loading for the $\mathrm{Cu}-\mathrm{ZSM}-5$ samples under investigation: gray triangle $\mathrm{Cu}-\mathrm{A}-\mathrm{L}$, filled triangle $\mathrm{Cu}-\mathrm{N}-\mathrm{L}$, filled circle $\mathrm{Cu}-\mathrm{C}-\mathrm{L}$, filled square $\mathrm{Cu}-\mathrm{A}-\mathrm{X}-\mathrm{L}$, and gray square $\mathrm{Cu}-\mathrm{A}-\mathrm{L}-\mathrm{P}$ 
suggests that the nature of co-cation does not alter the electronic properties of active copper species. Since the CT band at $22,700 \mathrm{~cm}^{-1}$ becomes visible only at higher copper loadings copper must be present in a different form for lower copper loadings.

To establish whether a relationship between the CT band intensity and catalytic activity exists, methanol was extracted from the samples after exposing the activated samples to methane. It is necessary to mention here that this methane to methanol process is not continuous (yet) and the operation of this catalyst cycle consists of three steps: (1) activation (calcination in oxygen or air) to deposit active oxygen, (2) reaction with methane, and (3) extraction of the formed products with a solvent.

The role of the extraction solvent on the methanol yield was investigated first. Extraction was performed immediately after reaction using different solvents. As an example, the amount of methanol extracted from $\mathrm{Cu}-\mathrm{A}-2.4$ using different solvents is shown in Fig. 3.

Clearly, more polar and protic solvents (ethanol, acetonitrile-water) yielded higher amounts of methanol produced. We propose that the role of the solvent is not only to dissolve the product, but also to provide protons to the reaction intermediate, most likely a methoxy species [33] formed on the catalyst surface to form methanol. Figure 4 displays the amount of methanol produced (ethanol was used as extraction solvent) as function of the CT band. Clearly, the amount of methanol produced increased linearly with increasing CT band intensity. Thus, we observed a quantitative relation between the $\mathrm{CT}$ band and the amount of methanol produced for Cu-ZSM-5 zeolites, indicating that the $\mathrm{CT}$ band at $22,700 \mathrm{~cm}^{-1}$ indeed represents the active site.

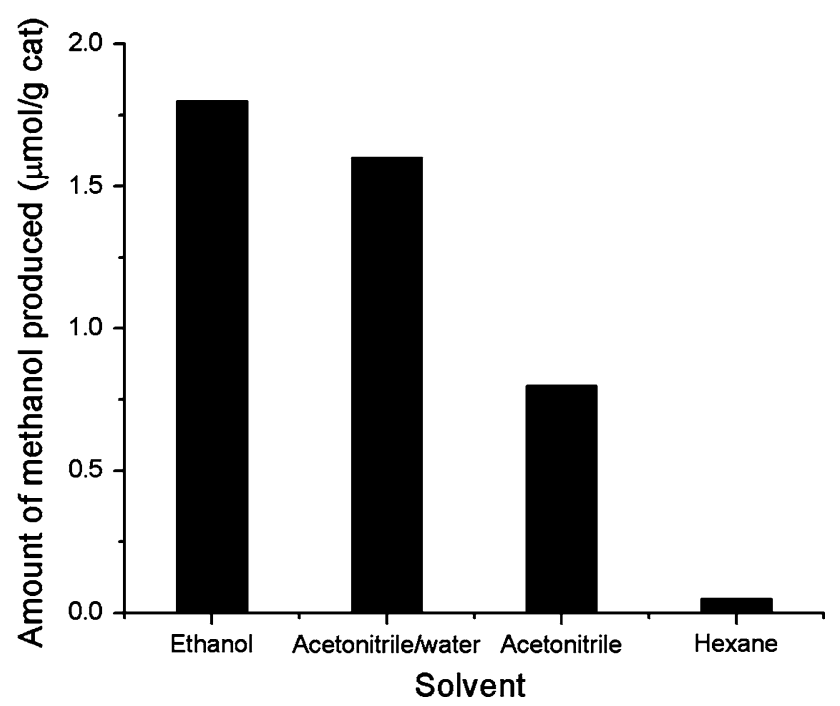

Fig. 3 Influence of the extraction solvent on the amount of methanol produced for $\mathrm{Cu}-\mathrm{A}-2.4$

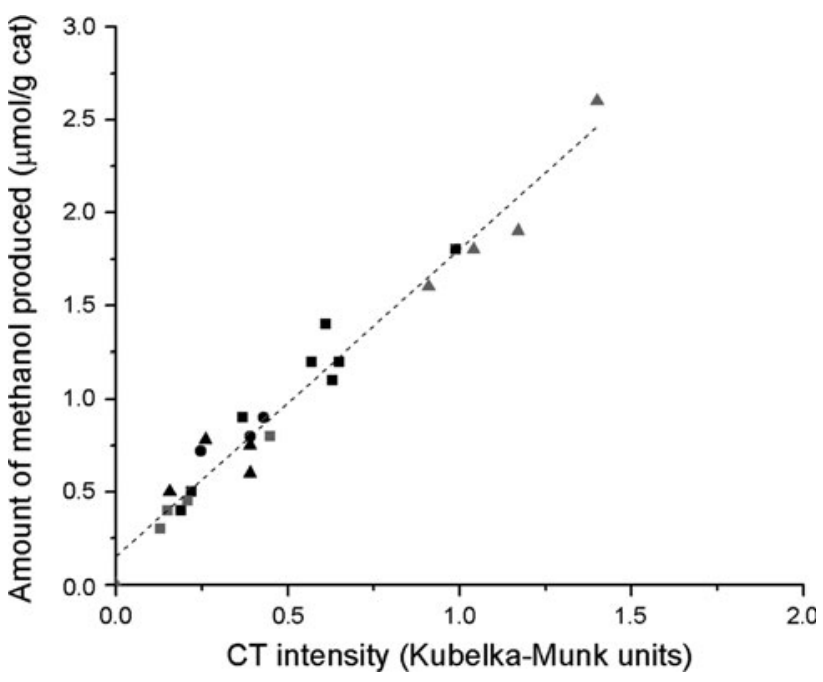

Fig. 4 The amount of methanol produced as a function of CT band intensity for $\mathrm{Cu}-\mathrm{ZSM}-5$ materials under investigation: gray triangle $\mathrm{Cu}-\mathrm{A}-\mathrm{L}$, filled triangle $\mathrm{Cu}-\mathrm{N}-\mathrm{L}$, filled circle $\mathrm{Cu}-\mathrm{C}-\mathrm{L}$, filled square $\mathrm{Cu}-\mathrm{A}-\mathrm{X}-\mathrm{L}$, and gray square $\mathrm{Cu}-\mathrm{A}-\mathrm{L}-\mathrm{P}$

As mentioned at least two types of copper species were present in the different Cu-ZSM-5 zeolites. Combining the catalytic results and UV-Vis-NIR DRS data we suggest that only a minority species are present in the active form. In order to get more insight into the copper speciation, we used TEM to directly visualize copper particles. Figure 5a shows a typical TEM image of $\mathrm{Cu}-\mathrm{A}-2.2$. The black spots indicate the presence of nanosized copper oxide particles $(2-5 \mathrm{~nm})$. The size of the particles leads us to speculate that they are on the outer surface of the ZSM-5 zeolite. Figure $5 \mathrm{~b}$ shows the presence of areas in the same sample without visible copper particles. Nevertheless in those areas EDX analysis did indicate the presence of copper. Therefore, this copper must be highly dispersed. It is tempting to assume that this highly dispersed copper is related to the $22,700 \mathrm{~cm}^{-1}$ band in the UV-Vis-NIR DRS data.

It is necessary here to mention that the time of exposure of the sample to the electron beam had a significant influence on the appearance of copper particles in TEM. Figure 6 shows TEM images of Cu-A-2.2 directly after exposure to the electron beam (a) and the same part of the sample after several minutes of exposure (b). It is clear that prolonged exposure to the electron beam appears to cause migration and sintering of copper to $2-5 \mathrm{~nm}$ particles [34]. This is an additional prove that part of the copper is highly dispersed within the channels of the ZSM-5 zeolites, which apparently migrated to the surface after long time exposure.

Summarizing, from TEM results it can be concluded that at least two types of copper species are present; i.e., nanosized copper oxide particles on the outer surface of the 

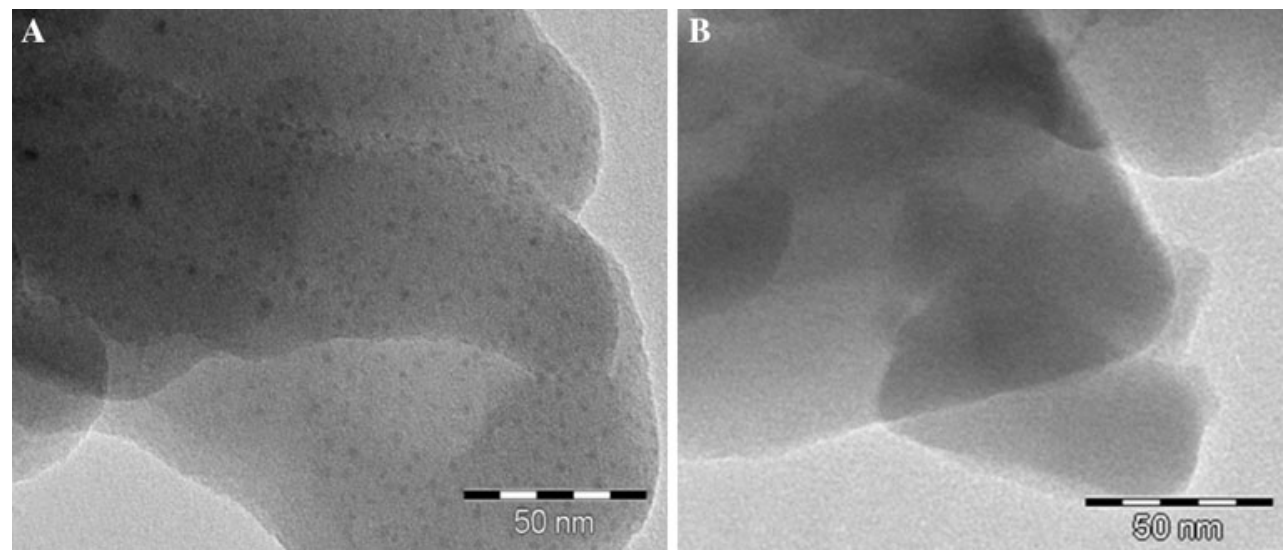

Fig. 5 TEM images of $\mathrm{Cu}-\mathrm{A}-2.4$. a $\mathrm{Cu}-\mathrm{O}$ clusters are present and $\mathbf{b}$ highly dispersed copper inside the channels
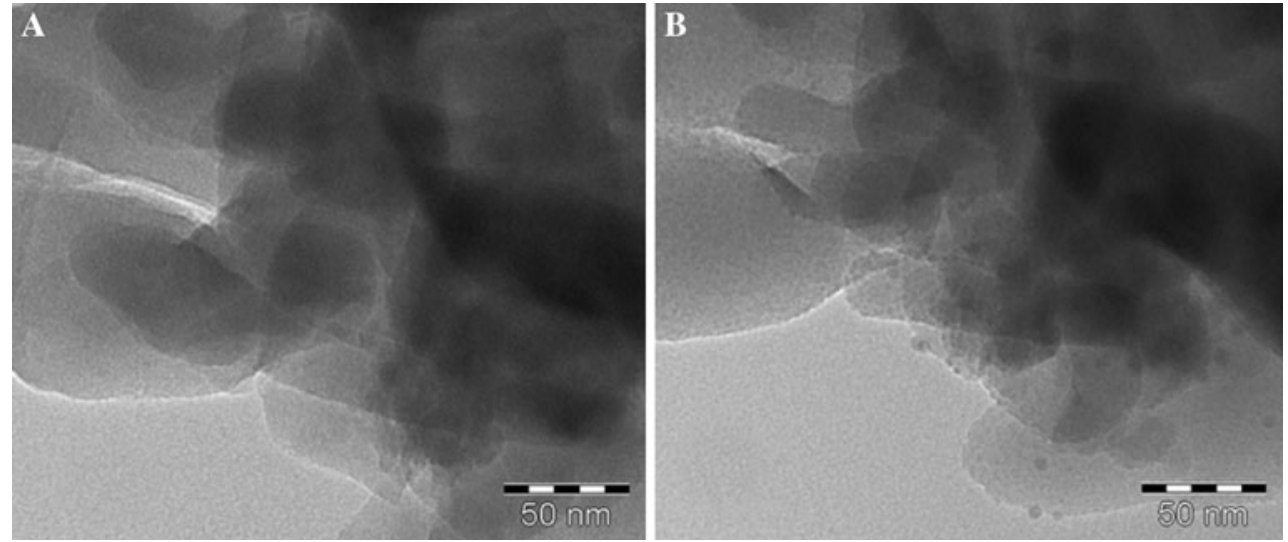

Fig. 6 TEM images of Cu-A-2.2 directly after exposure to the electron beam (a) and after few minutes exposure (b)

ZSM-5 zeolite and highly dispersed copper most probably inside the ZSM-5 channels.

To obtain additional information about the copper speciation and to correlate the amount of these species to catalytic activity, FT-IR measurements of adsorbed pivalonitrile and NO were performed. Pivalonitrile does not fit the pores of ZSM-5, but does adsorb on copper oxide [35, 36]. Therefore, its adsorption will be indicative for copper oxide on the outer surface of the zeolite (see also Supporting information for more details on the chosen approach). Next, NO is adsorbed to visualize copper inside the channels, if present. NO is a sensitive molecular probe for both $\mathrm{Cu}^{+}$and $\mathrm{Cu}^{2+}$, so it can be used to explore the valence and amount of copper in copper-exchanged zeolites [36]. Figure 7a shows FT-IR spectra of Cu-A-2.4 both after outgassing and after subsequent contact with pivalonitrile vapor. Bands at 2,239, 2,245, 2,280, and 2,296 $\mathrm{cm}^{-1}$ in the $\mathrm{CN}$-stretching region were formed after pivalonitrile adsorption. The former two bands have been assigned to the perturbation of the $\mathrm{CN}$ vibration by interaction of pivalonitrile with the terminal silanol groups and were also observed for the adsorption of pivalonitrile on a parent Na-ZSM-5. The band at $2,296 \mathrm{~cm}^{-1}$ has been associated to interaction of pivalonitrile with Lewis $\mathrm{Al}^{3+}$ site $[35,36]$, while the band at $2,280 \mathrm{~cm}^{-1}$ has been assigned to Lewis acid-base complex of pivalonitrile with $\mathrm{Cu}^{2+}[35,36]$.

Figure $7 \mathrm{~b}$ shows the FT-IR spectra of adsorbed pivalonitrile on Cu-ZSM-5 zeolites with varying metal loadings. In order to estimate the intensity of the absorption band at $2,280 \mathrm{~cm}^{-1}$ all spectra were deconvoluted (an example of such a deconvolution is included in the Supporting information). To investigate whether this FT-IR band relates to the active site the methanol yield was plotted as a function of the intensity of $2,280 \mathrm{~cm}^{-1}$ band. The result is shown in Fig. 8. There is no linear relationship between the $2,280 \mathrm{~cm}^{-1}$ IR band and the amount of methanol produced. It is concluded that the copper species on the outer surface that are probed by pivalonitrile are not involved in the methane to methanol reaction.

Subsequent to pivalonitrile, NO was adsorbed on the samples. Figure 9a shows a FT-IR spectrum of $\mathrm{Cu}-\mathrm{A}-2.4$ after adsorption of NO. Two intensive bands developed at 

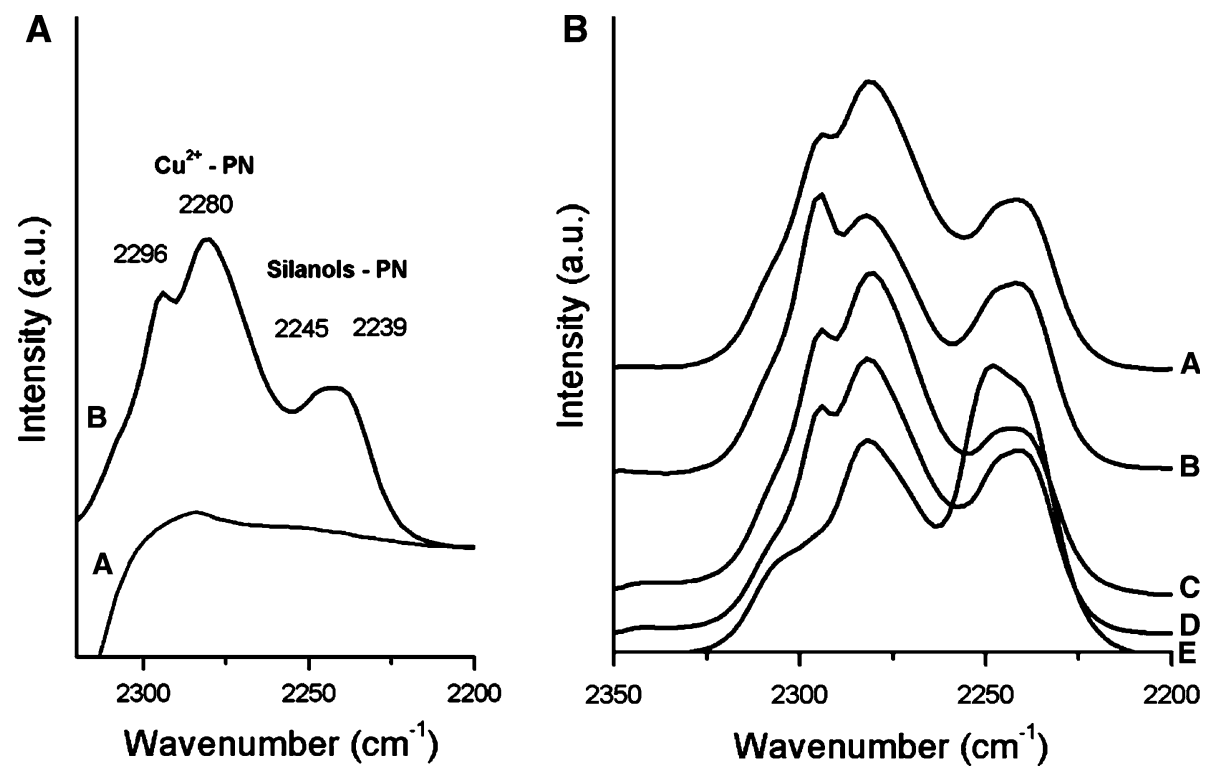

Fig. 7 a FT-IR spectra of Cu-A-2.4 after outgassing at $623 \mathrm{~K}$ for $1 \mathrm{~h}(A)$ and after adsorption of PN (7 mbar) at $323 \mathrm{~K}(B)$. b FT-IR spectra of Cu-ZSM-5 after adsorption of PN: A Cu-A-2.4, B Cu-A-2.5, C Cu-N-1.8, $B$ Cu-N-1.8, and $E$ Cu-A-0.9

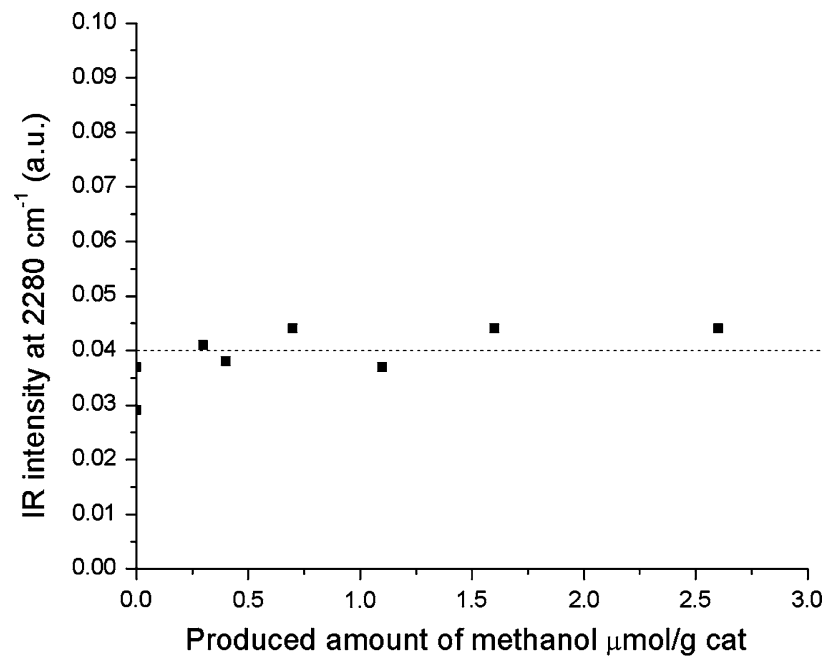

Fig. 8 Catalytic activity as a function of IR intensity of the absorption band at $2,280 \mathrm{~cm}^{-1}$ after pivalonitrile adsorption on the $\mathrm{Cu}-\mathrm{ZSM}-5$ samples under investigation

1,813 and $1,907 \mathrm{~cm}^{-1}$, which have been assigned to $\mathrm{NO}$ adsorbed on $\mathrm{Cu}^{+}$and $\mathrm{Cu}^{2+}$, respectively [37-41]. Figure $9 \mathrm{~b}$ shows the FT-IR spectra of NO adsorbed on Cu-ZSM-5 zeolites with different metal loadings. Apparently, the intensity of these bands increases with copper loading. The spectra were deconvoluted to determine the intensities of these two absorption bands. It was observed that $\mathrm{Cu}^{+}$was oxidized to $\mathrm{Cu}^{2+}$ during $\mathrm{NO}$ adsorption, therefore we used the total intensity of the bands at 1,813 and $1,905 \mathrm{~cm}^{-1}$ in further discussion (see also Supporting information for more details).

When the amount of methanol produced is plotted as a function of the total intensity of both NO IR-absorption bands, a linear relationship is observed (Fig. 10), indicating that NO (after pivalonitrile adsorption) is representative for the active sites, involved in methane oxidation.

Summarizing, also the IR adsorption data indicate that there are at least two copper species present in $\mathrm{Cu}-\mathrm{ZSM}-5$ zeolites under investigation: i.e., copper on the outer surface, which is not active for methane oxidation; and highly dispersed copper inside the channels of ZSM-5, which is involved in methane oxidation.

\section{Conclusions}

For activated Cu-ZSM-5 zeolites the CT band at $22,700 \mathrm{~cm}^{-1}$ is linearly related to the metal loading and to the activity of the samples for the production of methanol from methane and oxygen. Thus, a quantitative structureperformance relationship between the $\mathrm{CT}$ band intensity and the amount of methanol produced has been established. This relationship is valid irrespective of the used copper precursor, $\mathrm{pH}$, and the nature of charge compensating cation. The presence of at least two copper species was observed and confirmed by UV-Vis-NIR DRS, TEM, and FT-IR measurements. Part of the copper is present as $\mathrm{Cu}-\mathrm{O}$ nanoclusters on the outer surface. Based on catalytic experiments and FT-IR measurements of adsorbed pivalonitrile showed that $\mathrm{Cu}-\mathrm{O}$ species on the outer surface are inactive for methanol production. A minor part of copper is present inside the microporous channels as visualized by FT-IR of adsorbed NO after pivalonitrile adsorption, which most likely gives rise to the CT band at $22,700 \mathrm{~cm}^{-1}$. 

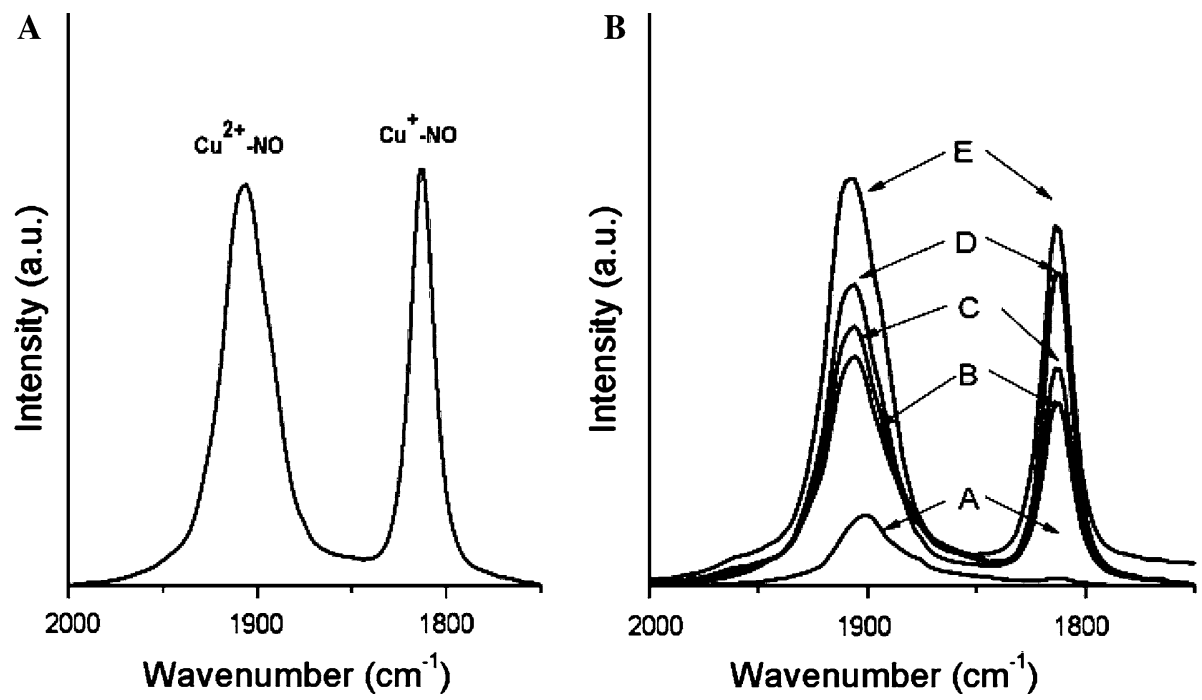

Fig. 9 a FT-IR spectrum of adsorption of NO 10 mbar $1 \%$ NO in He at $323 \mathrm{~K}$ on Cu-A-2.2. b FT-IR spectra of NO adsorption: $A$ Cu-A-0.9, $B$ $\mathrm{Cu}-\mathrm{N}-1.8, C \mathrm{Cu}-\mathrm{N}-2.0, D$ Cu-A-2.2, and $E$ Cu-A-2.6

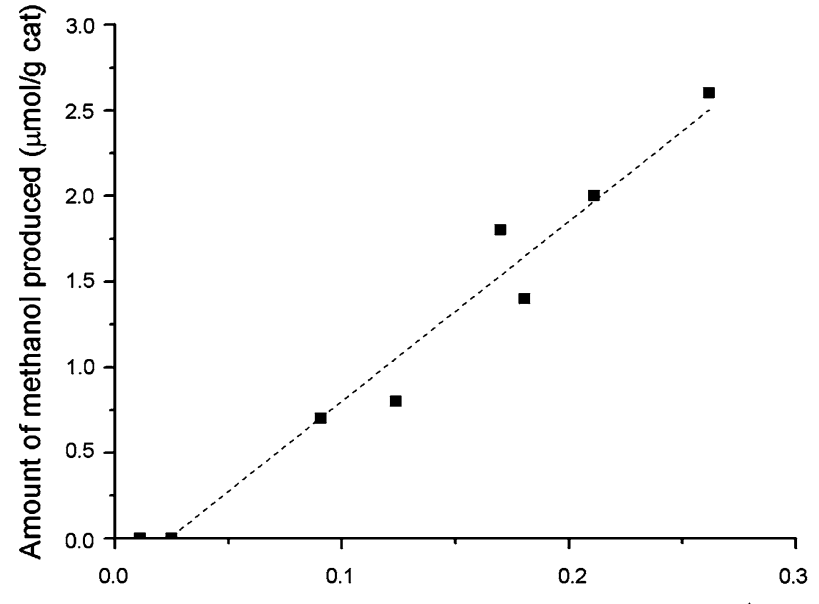

Intensity of IR absorption bands at 1813 and $1905 \mathrm{~cm}^{-1}$ (a.u.)

Fig. 10 The amount of methanol produced as a function of IR band at 1,813 and $1,907 \mathrm{~cm}^{-1}$ over Cu-ZSM-5 zeolites under investigation

These copper species inside the channels are involved in methane oxidation to methanol.

Acknowledgments Financial support was provided by ACTSASPECT (Project 053.62.006). The authors thank Cor van der Spek for TEM measurements.

Open Access This article is distributed under the terms of the Creative Commons Attribution Noncommercial License which permits any noncommercial use, distribution, and reproduction in any medium, provided the original author(s) and source are credited.

\section{References}

1. Finocchio E, Busca G, Lorenzelli V, Willey RJ (1995) J Catal 151:204
2. An Z, Pan X, Liu X, Han X, Bao X (2006) J Am Chem Soc 128:16028

3. Periana RA, Taube DJ, Evitt ER, Löffler DG, Wentreck PR, Voss G, Masuda T (1993) Science 259:340

4. Bar-Nahum I, Khenkin AM, Neumann R (2004) J Am Chem Soc 126:10236

5. Li F, Yuan G (2005) Chem Commun (17):2238

6. Liu Z-P, Hu P (2002) J Am Chem Soc 124:11568

7. Poels EK, Brands DS (2000) Appl Catal A Gen 191:83

8. Grunwaldt JD, Molenbroek AM, Topsøe N-Y, Clausen BS (2000) J Catal 194:452

9. Basimi L, Pioversan L (1998) Ind Eng Chem Res 37:258

10. Sobolev VI, Dubkov KA, Panna OV, Panov GI (1995) Catal Today $24: 251$

11. Dubkov KA, Sobolev VI, Talsi EP, Rodkin MA, Watkins NH, Shteinman AA, Panov GI (1997) J Mol Catal A Chem 123:155

12. Panov GI, Sobolev VI, Kharitonov AS (1990) J Mol Catal 61:85

13. Jia J, Pillai KS, Sachtler WMH (2004) J Catal 221:119

14. Hensen EJM, Zhu Q, van Santen RA (2005) J Catal 223:136

15. Pirngruber GD, Roy PK, Prins R (2006) Phys Chem Chem Phys $8: 3939$

16. Kubacka A, Wang Z, Sulikowski B, Cortés Corberán V (2007) J Catal 250:184

17. Shibata Y, Hamada R, Ueda T, Ichihashi Y, Nishiyama S, Tsuruya $S$ (2005) Ind Eng Chem Res 44:8765

18. Groothaert MH, Smeets PJ, Sels BF, Jacobs PA, Schoonheydt RA (2005) J Am Chem Soc 127:1394

19. Smeets PJ, Groothaert MH, Schoonheydt RA (2005) Catal Today 110:303

20. Beznis NV, Weckhuysen BM, Bitter JH (2010) Catal Lett 136:52

21. Praliaud H, Mikhailenko S, Chajar Z, Primet M (1998) Appl Catal B Environ 16:359

22. Itho Y, Nishiyama S, Tsuruya S, Masai M (1994) J Phys Chem 98:960

23. de Carvalho MCNA, Passos FB, Schmal M (2000) Appl Catal A Gen 193:265

24. Smeets PJ, Groothaert MH, van Teeffelen RM, Leeman H, Hensen EJM, Schoonheydt RA (2007) J Catal 245:358

25. Groothaert MH, Lievens $\mathrm{K}$, Leeman H, Weckhuysen BM, Schoonheydt RA (2003) J Catal 220:500 
26. Woertink JS, Smeets PJ, Groothaert MH, Vance MA, Sels BF, Schoonheydt RA, Solomon EI (2009) Proc Natl Acad Sci USA 106:18908

27. Lever ABP (1984) Inorganic electronic spectroscopy, 2nd edn. Elsevier, Amsterdam

28. Weckhuysen BM, Schoonheydt RA (1999) Catal Today 49:441

29. Battiston AA, Bitter JH, de Groot FMF, Overweg AR, Stephan O, van Bokhoven JA, Kooyman PJ, Van, der Spek C, Vanko G, Koningsberger DC (2003) J Catal 213:251

30. Weckhuysen BM, Schoonheydt RA (2000) Electronic Spectroscopies. In: Weckhuysen BM, Van der Voort P, Catana G (eds) Spectroscopy of transition metal ions on surfaces. Leuven University Press, Leuven

31. Wichterlová B, Dědecěk J, Sobalík Z, Vondrová A, Klier K (1997) J Catal 169:194

32. Dalconi MC, Cruciani G, Alberti A, Ciambelli P (2006) Microporous Mesoporous Mater 94:139

33. Steghuis GEA, van Ommen JG, Seshan K, Lercher JA (1997) Stud Surf Sci Catal 107:403
34. Chupin C, van Veen AC, Konduru M, Després J, Mirodatos C (2006) J Catal 241:103

35. Montanari T, bevilacqua M, Busca G (2006) Appl Catal A Gen 307:21

36. Montanari T, Bevilacqua M, Resini C, Busca G, Pirone R, Ruoppolo G (2007) J Porous Mater 14:291

37. Turnes Palomino G, Bordiga S, Zecchina A, Marra GL, Lamberti C (2000) J Phys Chem B 104:8641

38. Prestipino C, Berlier G, Llabrés FX, Xamena I, Spoto G, Bordiga S, Zecchina A, Turnes Palomino G, Yamoto T, Lamberti C (2002) Chem Phys Lett 363:389

39. Dědecěk J, Sobalík Z, Tvaružková Z, Kaucký D, Wichterlová B (1995) J Phys Chem 99:16327

40. Lamberti C, Bordiga S, Salvalaggio M, Spoto G, Zecchina A, Geobaldo F, Vlaic G, Bellatreccia M (1997) J Phys Chem B 101:344

41. Hoost TE, Laframboise KA, Otto K (1995) Appl Catal B Environ 7:79 